\title{
Sustainability, insularity, Pareto and the paradox of Schrödinger
}

\author{
V. S. Pescador \\ Investigation Project, Las Palmas de Gran Canaria University, Spain
}

\begin{abstract}
The evolution of transport systems in recent decades arising from fast and cheap access to the fossil energy has resulted in the expansion of public mass transport and therefore the colonization of territories that otherwise would be unthinkable. The phenomenon of tourism developed in Northern France and Southern England by Thomas Cook in the second half of the 20th century joined with the new means of transport, provided the possibility to move enormous amounts of people from one territory to another, colonizing it and extending its capacities. If we put together this with the expansion of sun and beach tourism in island territories around the 60s we can have an explosive combination. Most of the islands with large rates of tourism, as is the case with the Canary Islands, have been developed under the umbrella of a high floating tourist population that is able to support, through the development of the tourist industry, a huge, disproportionate and growing local population. This economic system has its basis in the maintenance of the current conditions of air transport prices, responsible for the tourism industry. In the current world energy crisis concert in which we operate with a continuous increase in fuel prices, and being that air transport is the most fossil dependent system by consumption and distance, the future of these destinations becomes uncertain, and local populations in the majority of cases has spent by far the load capacity of the territory and therefore could be pushed to a process of emigration. Thus, a study of the current situation of islands transport, its foreseeable evolution and possible competitors is essential, in order to develop a sustainable tourism model and thus calibrate future capabilities of the sector and an absolutely dependent economy of it. It is in my opinion the paradigm of a transport system in which society, economy,
\end{abstract}


and territory depends on the confluence of all three, not only represents the basis of the sustainability, but in this case ends up with an imperative need for subsistence.

Keywords: air transport system, mass tourism, energy cost, load capacity, islands transport, tourist industry.

\section{Introduction}

The Canary Islands are in the outermost region of the European Union. It is made up of seven major islands: El Hierro, La Gomera, La Palma and Tenerife, Fuerteventura, Gran Canaria and Lanzarote. The archipelago is located at the northwest coast of Africa, between the coordinates $27^{\circ} 37^{\prime}$ and $29^{\circ} 25^{\prime}$ of North latitude and $13^{\circ} 20^{\prime}$ and $18^{\circ} 10^{\prime}$ West longitude, the distance to the African continent is just $95 \mathrm{~km}$ at the closest point (figure 1).

These islands, of volcanic origin, are part of the natural region of Macaronesia. Its climate is subtropical, though modified by the height and the north side or South, Canary has four National Parks and several islands are of UNESCO biosphere reserves. They are visited each year by more than 12 million tourists.
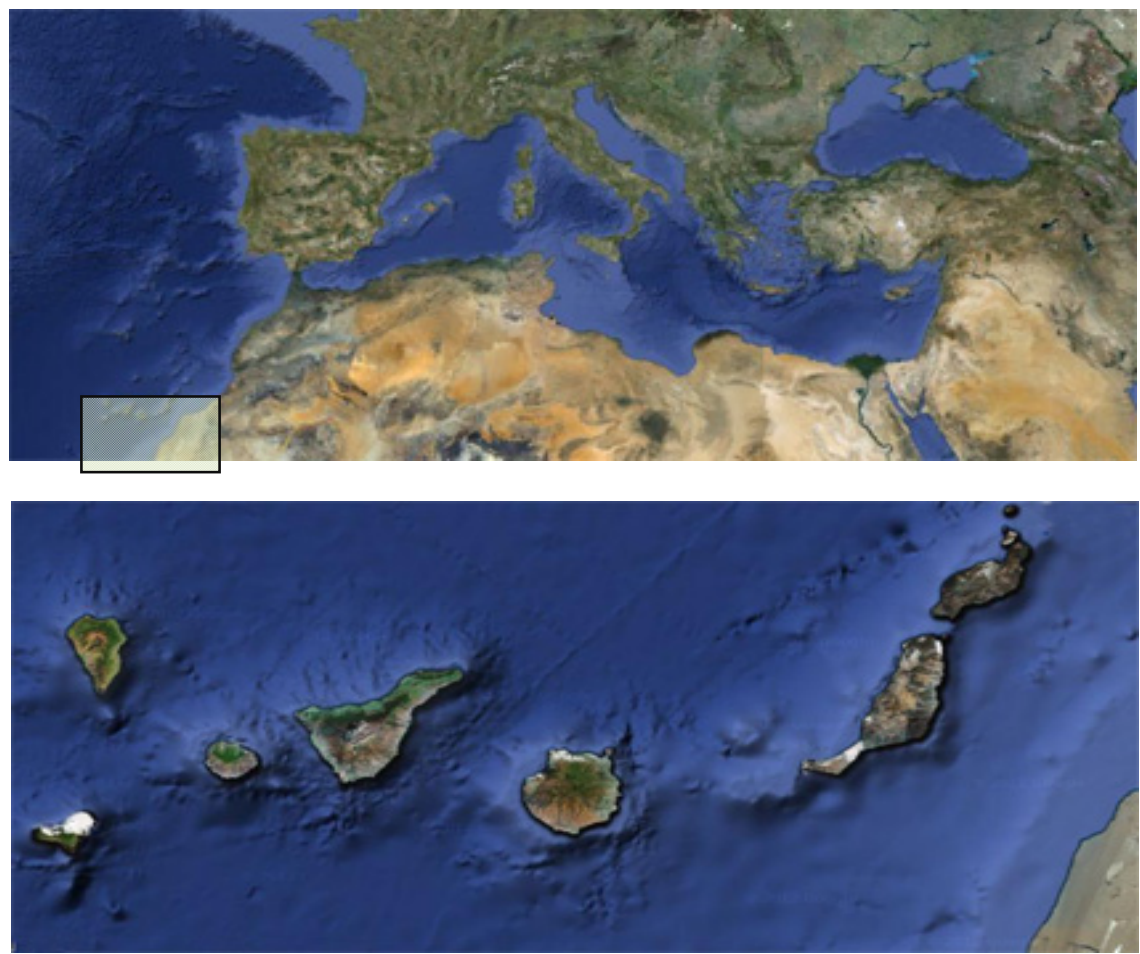

Figure 1: $\quad$ Geographical location, Canary Islands [2]. 
The natural Islands population is 2.126.769 inhabitants, in a surface of $7,447 \mathrm{~km}^{2}$ which gives a population density of 286 people per square kilometer, one of the highest densities in Europe, the floating tourist population is 12,354,212 tourists/year, approximately 1,029,517 tourists/month. One hundred percent of tourism reaches the islands using the aircraft as a means of transport, therefore taking into account that transport and connections are the cornerstones of any tourist destination, in the insular case turns into a fundamental value and especially when the economy of the Islands depends mainly from this sector.

\section{The outlook of island air transport}

Tourism is the first industry in the archipelago with a weight of $30 \%$ of the GDP (gross domestic product) of the Canary Islands economy, without quantifying the indirect income that this sector moves, and is also responsible for the $32 \%$ of the direct employment. The following graph quantified by issuing origin countries the number of passengers who arrived to the Islands in the years 2011 and 2012 [1] (table 1).

Table 1: Passengers from abroad according to country of origin in the autonomous community of the Canary Islands. Data IDEA Canary Island Government [1].

\begin{tabular}{l}
\hline \multicolumn{1}{|c|}{ YEAR } \\
\begin{tabular}{|l|}
\hline GERMANY \\
\hline AUSTRIA \\
\hline BELGIUM \\
\hline DENMARK \\
\hline RUSSIA \\
\hline FINLAND \\
\hline FRANCE \\
\hline UNITED KINGDOM \\
\hline HOLAND \\
\hline IRELAND \\
\hline ITALY \\
\hline NORWAY \\
\hline CZECH REPUBLIC \\
\hline POLAND \\
\hline SWEDEN \\
\hline SWITZERLAND \\
\hline PORTUGAL \\
\hline OTHER COUNTRIES \\
\hline \multicolumn{2}{|c|}{ TOTAL................. } \\
\hline
\end{tabular}
\end{tabular}

\begin{tabular}{|c|c|c|c|}
\hline \multicolumn{4}{|c|}{ JANUARY-DECEMBER } \\
\hline 2011 & 2012 & Difference & Percentage \\
\hline $2,720,153$ & $2,642,638$ & $-77,515$ & $-2.85 \%$ \\
\hline 107,005 & 110,064 & 3,059 & $2.86 \%$ \\
\hline 354,655 & 354,625 & -30 & $-0.01 \%$ \\
\hline 321,315 & 321,956 & 641 & $0.20 \%$ \\
\hline 69,129 & 90,470 & 21,341 & $30.87 \%$ \\
\hline 267,251 & 263,595 & $-3,656$ & $-1.37 \%$ \\
\hline 197,140 & 208,065 & 10,925 & $5.54 \%$ \\
\hline $3,625,810$ & $3,511,210$ & $-114,600$ & $-3.16 \%$ \\
\hline 410,254 & 423,420 & 13,166 & $3.21 \%$ \\
\hline 405,201 & 378,260 & $-26,941$ & $-6.65 \%$ \\
\hline 298,086 & 237,527 & $-60,559$ & $-20.32 \%$ \\
\hline 437,404 & 458,877 & 21,473 & $4.91 \%$ \\
\hline 36,133 & 30,968 & $-5,165$ & $-14.29 \%$ \\
\hline 147,380 & 151,817 & 4,437 & $3.01 \%$ \\
\hline 443,242 & 450,769 & 7,527 & $1.70 \%$ \\
\hline 212,061 & 228,296 & 16,235 & $7.66 \%$ \\
\hline 63,314 & 53,522 & $-9,792$ & $-15.47 \%$ \\
\hline 202,645 & 185,414 & $-17,231$ & $-8.50 \%$ \\
\hline $10,318,178$ & $10,101,493$ & $-216,685$ & $-2.10 \%$ \\
\hline
\end{tabular}

If we study in detail the recent developments in air transport we realize that it is one of the sectors that has most suffered the structural changes that are taking 
place in the global economy since the crisis of the oil prices in the 2006/2008 during which the barrel became about $142 \$$ USA.

Currently the rising prices of oil, the new Low cost companies, the investments made in the field of aviation safety from the terrorist attacks of $9 / 11$, the use of new technologies online for purchase and consultation of air services and the global economic crisis of the past years have been all determining factors that have pushed many leading companies to processes of fusion or disappearance irrespective of its way of operate, regular, Charter or Low cost. Because of this set of events companies have focused on reducing costs while maintaining and prioritizing the maximum occupancy lines thereby reducing the number of operations and closing lines to tourist destinations among others, or changing the marketing of the product using the supplementary income, i.e., "pay-for service used" limiting hand baggage, weight, volume etc., charging on the basis of the transferred kilos what makes more expensive the flight ticket for long stay destinations (over one week) and the leisure sports requiring transfer of material as the case of the Canary Islands and in general the majority of Island Sun and beach destinations. This has forced these destinations to reduce costs to be more competitive, resulting in a loss of the quality of service that leads to a deterioration in the infrastructure which entails a gradual decrease in visitors to the destination in the short term and enter a vicious circle which again ends in loss of passengers and flights reduced, the curve of the process follows the pattern of the Gauss campaign with a peak and a quick and pronounced decline.

In the five large airports of the Island operate the major European airlines in a total of 47 with 166 air connections throughout the year due to the fantastic weather conditions and the climate which allows no seasonality tourism [3], table 2.

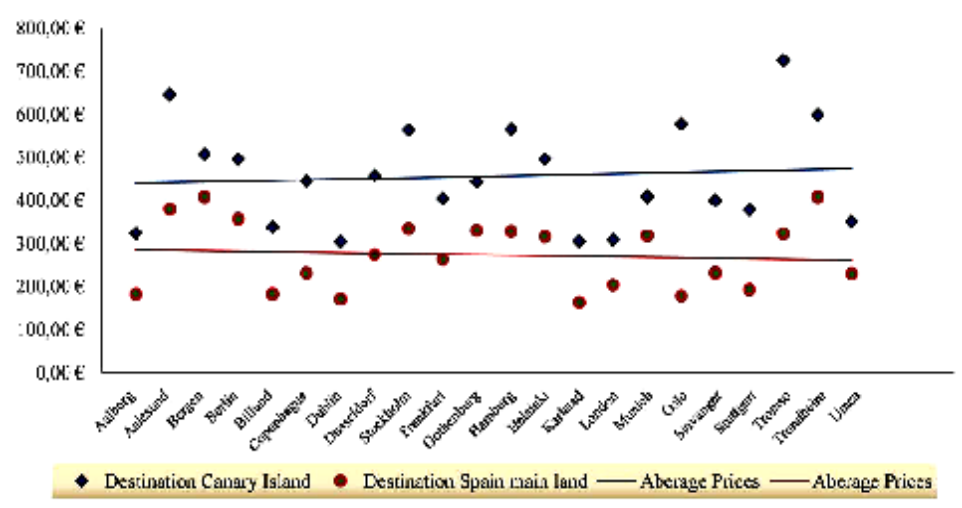

Figure 2: $\quad$ Average price per destination. 
If we look at table 1, the main markets are in the United Kingdom, Germany, Benelux, Norway and Sweden, with average price to the Islands in air transport as indicated in figure 2. By the costs per route per distance travelled is extracted an arithmetic mean of cost per passenger every $100 \mathrm{~km}$. of distance that is around the figure of $11,96 € / 100 \mathrm{~km}$ for the Canary Islands and 12,70€/100 km for destination Spain (mainland) as competitor.

As we see in figure 2, the average lines of travel costs have a different of $40 \%$ between the Canary Islands and its competitors, and those lines will not remain parallel as the fuel prices go up, the distance between them would increase

Table 2: $\quad$ Air connections and companies by Islands [3].

\begin{tabular}{|c|c|c|c|c|c|c|c|c|}
\hline \multicolumn{2}{|l|}{ AIRLINE } & \multicolumn{7}{|c|}{ CONNECIION WIIH } \\
\hline Name & Nacionality & Gran Canaria & \begin{tabular}{|l|} 
Tenerife \\
\end{tabular} & Lanzarote & Fuerteventur: & La Palma & La Gomera & El Hierro \\
\hline AIR BERLIN & Germany & Yes & Yes & Yes & Yes & Yes & No & No \\
\hline CONDOR & Germany & Yes & Yes & Yes & Yes & Yes & No & No \\
\hline EXCEL AIRWAYS GERMANY & Germany & Yes & Yes & No & Yes & No & No & No \\
\hline FLYNIKI & Germany & Yes & Yes & Yes & Yes & Yes & No & No \\
\hline HAMBURG INTERNATIONAL & Germany & Yes & Yes & Yes & Yes & Yes & No & No \\
\hline TUI FLY & Germany & Yes & Yes & Yes & Yes & No & No & No \\
\hline LUFTHANSA & Germany & Yes & Yes & Yes & Yes & No & No & No \\
\hline AUSTRIAN AIRLINES & Austria & Yes & Yes & Yes & Yes & No & No & No \\
\hline LAUDA AIR & Austria & Yes & Yes & Yes & No & No & No & No \\
\hline AIR LINE CABO VERDE & Cabo Verde & Yes & No & No & No & No & No & No \\
\hline FINNAIR & Scandinavia & Yes & Yes & Yes & Yes & No & No & No \\
\hline NORWEGIAN AIR & Scandinavia & Yes & Yes & Yes & No & No & No & No \\
\hline NOVAIR & Scandinavia & Yes & Yes & Yes & Yes & No & No & No \\
\hline STERLING AIRLINES & Scandinavia & Yes & Yes & No & No & No & No & No \\
\hline AIR EUROPA & Spain & Yes & Yes & Yes & Yes & No & No & No \\
\hline BINTER CANARIAS & Spain & Yes & Yes & Yes & Yes & Yes & Yes & Yes \\
\hline CLICKAIR & Spain & Yes & Yes & No & No & No & No & No \\
\hline IBERIA & Spain & Yes & Yes & Yes & Yes & Yes & No & No \\
\hline ISLAS AIRWAYS & Spain & Yes & Yes & Yes & Yes & Yes & No & No \\
\hline SPANAIR & Spain & Yes & Yes & Yes & Yes & No & No & No \\
\hline VUELING & Spain & Yes & Yes & No & No & No & No & No \\
\hline IBERWORLD & Europe & Yes & Yes & Yes & Yes & No & No & No \\
\hline EXCEL AIRWAYS FRANCE & France & No & No & No & No & No & No & No \\
\hline OLYMPIC AIRLINES & Greece & No & No & No & No & No & No & No \\
\hline EASYJ ET & England & Yes & Yes & Yes & Yes & No & No & No \\
\hline FIRST CHOICE & England & Yes & Yes & Yes & Yes & No & No & No \\
\hline FLY MONARCH & England & Yes & Yes & Yes & Yes & No & No & No \\
\hline FLY THOMAS COOK & England & Yes & Yes & Yes & Yes & No & No & No \\
\hline GLOBESPAN AIRWAYS & England & Yes & Yes & Yes & No & No & No & No \\
\hline JET2 & England & NO & Yes & Yes & No & No & No & No \\
\hline THOMAS COOK AIRLINES & England & Yes & Yes & Yes & Yes & No & No & No \\
\hline THOMSON FLY & England & Yes & Yes & Yes & Yes & Yes & No & No \\
\hline FLIGHTLINE & England & Yes & Yes & Yes & Yes & Yes & No & No \\
\hline AIR LINGUS & Ireland & Yes & Yes & Yes & No & No & No & No \\
\hline EUROFLY & Italy & No & Yes & No & Yes & No & No & No \\
\hline NEOS & Italy & Yes & Yes & Yes & Yes & No & No & No \\
\hline FLYLAL & Lithuania & Yes & Yes & No & No & No & No & No \\
\hline LUXAIR & Luxembourg & Yes & Yes & Yes & Yes & No & No & No \\
\hline TOP FLY & Morocco & Yes & No & No & No & No & No & No \\
\hline AIR MAURITANIE & Mauritania & Yes & No & No & No & No & No & No \\
\hline SAS & Norway & Yes & Yes & No & No & No & No & No \\
\hline JETAIR & Netherlands & Yes & Yes & Yes & Yes & Yes & No & No \\
\hline TRANSAVIA & Netherlands & Yes & Yes & Yes & Yes & Yes & No & No \\
\hline EUROATLANTIC AIRWAYS & Portugal & Yes & Yes & Yes & Yes & No & No & No \\
\hline SATA & Portugal & Yes & No & No & No & No & No & No \\
\hline SMART WINGS & Czech Republ & Yes & Yes & No & No & No & No & No \\
\hline TRAVEL SERVICE & Czech Republ & Yes & Yes & Yes & Yes & No & No & No \\
\hline EDELWEISS AIR & Switzerland & Yes & Yes & Yes & Yes & No & No & No \\
\hline HELLO AG & Switzerland & Yes & No & No & Yes & No & No & No \\
\hline
\end{tabular}

\begin{tabular}{|l|l|l|l|l|l|l|l|}
\hline Total number of air connections by Island & 45 & 42 & 34 & 32 & 11 & 1 & 1 \\
\hline
\end{tabular}


significantly, take note that the $40 \%$ of the tour operators' income is dedicated to transport and obviously this is a very important competitiveness index.

\section{The trend of energy markets}

The adjustments made by the airlines which have resulted in a new business model based on maximum cost reduction and the use of the higher carrying capacity per unit of air displacement, are a direct result of the absolute industry dependence on the fuel prices, a standard plane consumes an average of $3.5 \mathrm{l}$. of kerosene per each $100 \mathrm{~km}$ and seat offered on long-haul routes as it is the case of the Canary Islands from markets issuers from central Europe [4] (table 4 and Figure 1).

Table 3: $\quad$ Fuel consumption of aircraft per seat per $100 \mathrm{~km}$.

\begin{tabular}{cccccc}
\hline Year & Total fuel & Factor Fuel & Operations & Fuel 100 & Range \\
\hline $\mathbf{2 0 0 8}$ & 1469776470 & 104072,748 & 29579 & 3,51846743 & $\mathrm{~L}$ \\
$\mathbf{2 0 0 7}$ & 1398970301 & 95566,2205 & 27035 & 3,53490736 & $\mathrm{~L}$ \\
$\mathbf{2 0 0 6}$ & 1357147242 & 91191,6055 & 25670 & 3,55245834 & $\mathrm{~L}$ \\
$\mathbf{2 0 0 5}$ & 1284300365 & 86342,4165 & 23898 & 3,61295575 & $\mathrm{~L}$ \\
$\mathbf{2 0 0 4}$ & 1124145421 & 76728,2614 & 21235 & 3,61329227 & $\mathrm{~L}$ \\
$\mathbf{2 0 0 3}$ & 967581713 & 67506,9752 & 18604 & 3,62862692 & $\mathrm{~L}$ \\
$\mathbf{2 0 0 2}$ & 904776547 & 64399,3598 & 18007 & 3,57635141 & $\mathrm{~L}$ \\
$\mathbf{2 0 0 1}$ & 944133660 & 66156,7757 & 18736 & 3,53099785 & $\mathrm{~L}$ \\
$\mathbf{2 0 0 0}$ & 974856116 & 68329,5932 & 18504 & 3,69269311 & $\mathrm{~L}$ \\
$\mathbf{1 9 9 9}$ & 901353879 & 62292,0686 & 16149 & 3,85733288 & $\mathrm{~L}$ \\
\hline
\end{tabular}

The evolution of kerosene prices in recent years in which there has been an explosion of air transport worldwide mostly thanks to the markets of emerging countries, has been linked to the prices of oil as a primary energy source, and Figure 2 shows the evolution of average kerosene prices at \$/t (dollars per ton) in green, along with the number of passengers, the number of air operations and goods traffic, data obtained from the statistical bulletins of hydrocarbons and the AENA data centre. We can see haw kerosene consumption reaches its peak in 2007 slightly down the effect of the economic crisis and the increase of fuel prices, the first energy crisis of air transport in 2008 has been drawn by air carriers on the basis of increasing efficiency and optimizing the load reducing expenses, however if we look at the evolution of average crude oil barrel prices since the 1980s we see how the upward trend is continuing (figure 3).

As shown we are coming shortly again after the values of the year 2008, and the trend is to continue increasing the price, Figure 5 reflects the number of tourists received by the Islands in the period 2000-2012 and clearly during the years 2008, 2009 and 2010 can be seen a significant decrease in the number of arrivals in good part motivated by the diversion of large operators to other 
competitive destinations in price per transport unit mostly of continental Spain, North Africa and Turkey, and being recover in the years 2011 and 2012 cause of the eruption of the so-called "Arab spring”. Paraphrasing the late Matt Simmons, icon of the oil industry, in the escalation of prices, there are two pending to cushion the fall, one can be a soft fall; the other an abrupt and uncontrolled fall, and the abrupt fall is which is reflected in the unstoppable rise of the oil price, which is causing a damage of yet unknown proportions for the air transport sector and therefore the dependent tourism.

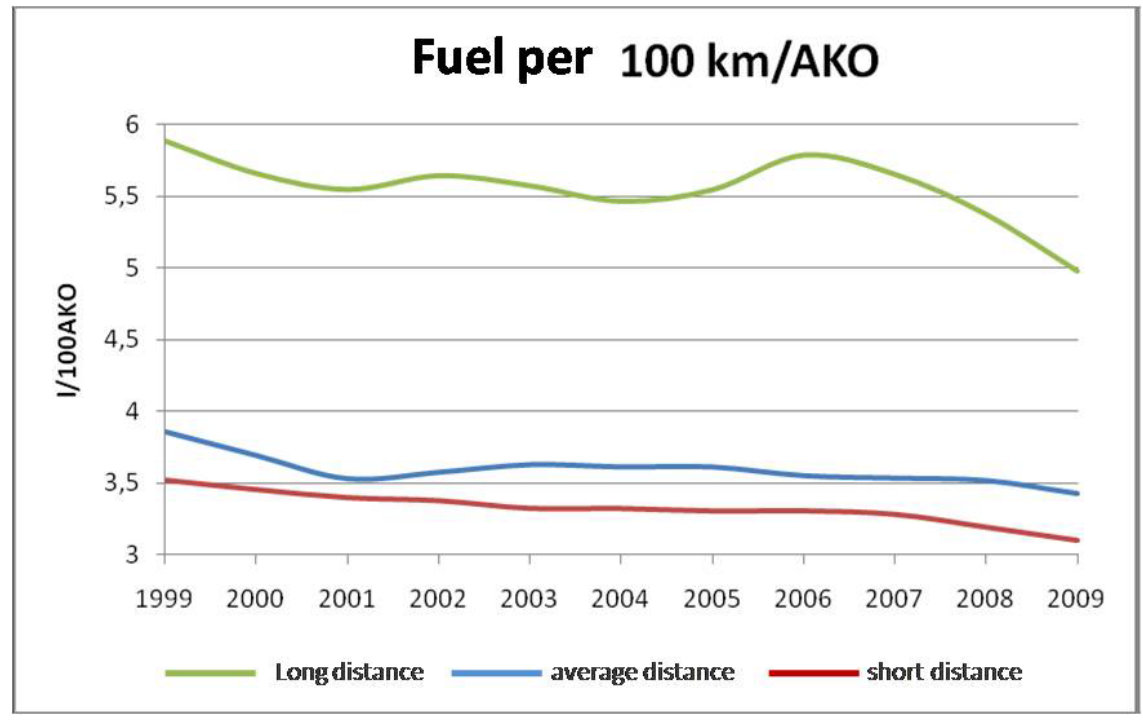

Figure 3: $\quad$ Ratio of consumption of fuel per $100 \mathrm{~km}$.

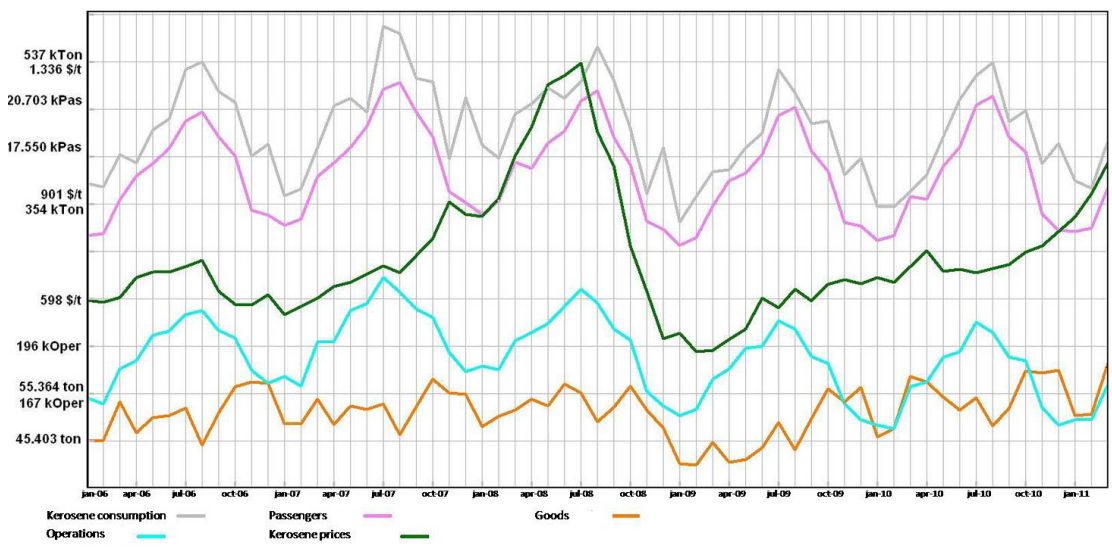

Figure 4: $\quad$ Prices of kerosene, flight operations and number of passengers. 


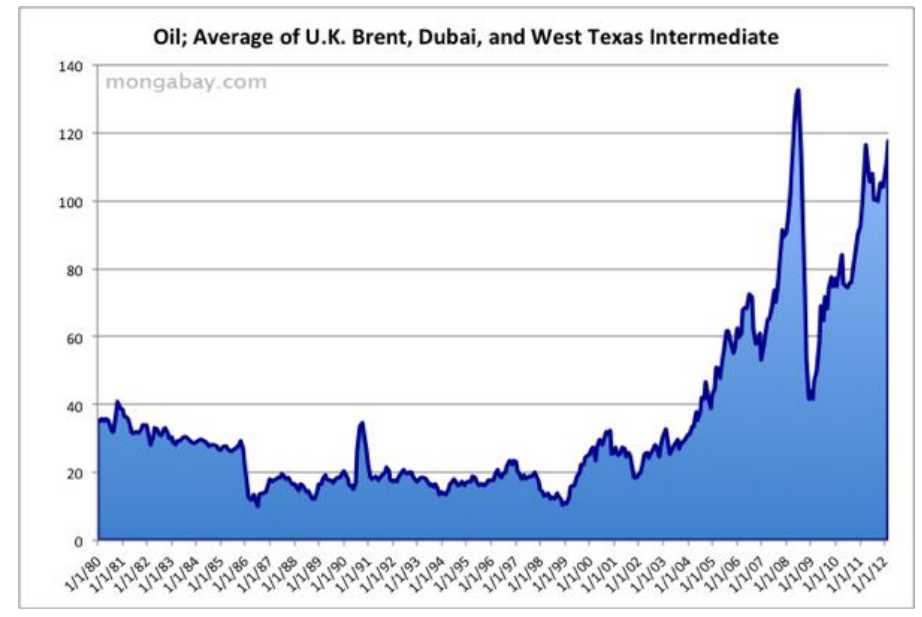

Figure 5: Evolution of the prices of a barrel of oil.

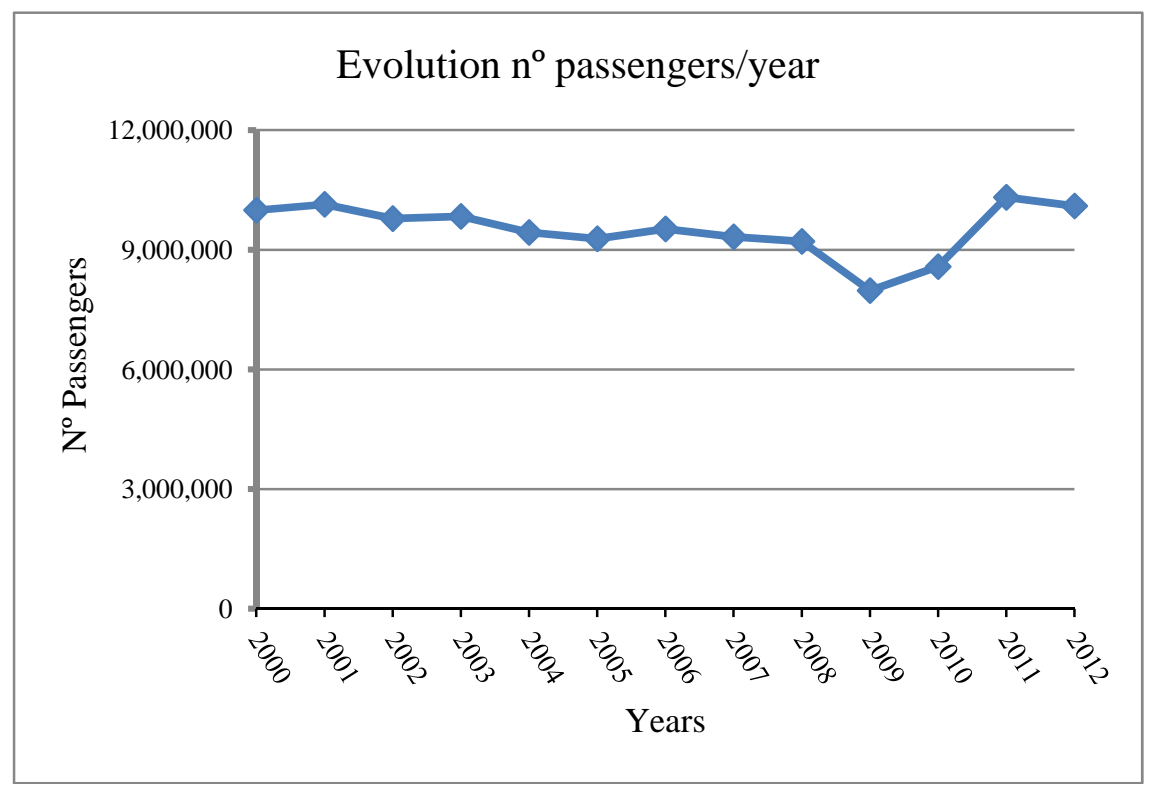

Figure 6: Evolution of the number of passengers per year.

If the average expenditure per tourist and day is $133.42 €\left(4^{\text {th }}\right.$ quarter of 2011 per German tourist), and the cost due to transportation is $39.23 €$ per tourist per day, we can apply the principle of the Italian Economist Wilfredo Pareto (known by the $80 / 20$ rule) which postulates that $80 \%$ of consequences (target expenditure) depends on the $20 \%$ of the causes (air transport expenditure), if this 
balance scale breaks, the destination ceases to be competitive for this mass tourism, Sun and beach, and we are heading inevitably tower it which will result in a disaster for the economy of the island's pushing the population to a mass exodus.

Let us see which are the expectations of evolution of prices of primary energy; in the following figure 4 you can see the curves of the decline of oil production according to the theory of the Hubbert peak for the major oil regions in the world until 2050. The pink layer represents the production in the area of the Middle East where would have reached its "peak" at the end of the last decade and the beginning of the present, this implies that we have a scenario of gradual reduction of the quantity of primary energy and an increase rise of the extraction of resources more and more complicated, which leads to the increase of energy prices generally, and inevitably the kerosene in particular, and this is happening already, therefore we are faced with a dizzying scenario over the next 30 years of progressive increase of the fuel prices which will affect the cost of air transport.

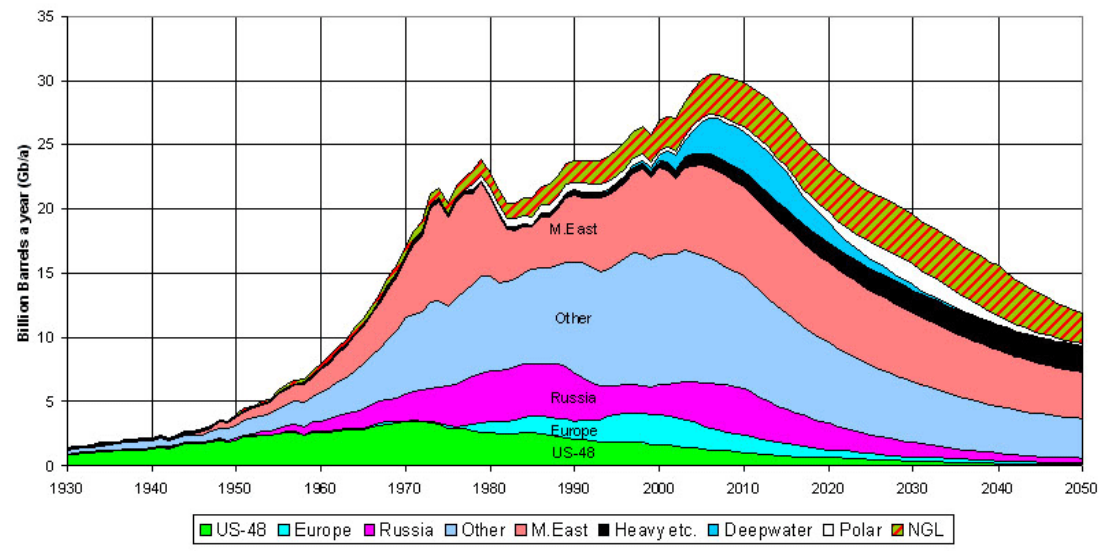

Figure 7: $\quad$ The world oil reserves.

\section{The current scene}

Major companies and manufacturers have long working in this scenario on the basis of two lines of work, in one hand the design of aircraft operating at high altitudes which reduces consumption and significantly reduces the time travel (Stratoliner) and on the other the increase in load capacity to decrease the cost per passenger and $\mathrm{km}$. (the EMIT of NASA or the new Airbus), but the question is how long will hold up our current model of air transport? For Paul Wylde, consultant of Boeing, the answer is emphatic "30 years". If the World Tourism Organization (UNWTO) presents a growing trend of the tourism sector for the next years with rates of growth around 5\% annually, on which basis of transportation rests its growth?, we are faced with the paradox of Schrödinger, 
which may work for quantum physics but not for real life, if we keep the cat (air transport) in the box it will not remain in two State at the same time (live and dead), we better open the box before it is too late, in the majority of directly dependent destinations on air transport haven't even developed emergency protocols to the possibility of an excessive cost of transport.

Canary Islands Airports still intends enlargement at base to increase the amount of tracks when the number of air operations is in decline and the terminals are not adapted to accommodate the new aircraft with more carrying capacity and size, it is necessary to closely follow patterns of the Aeronautics industry and research on fuels based on biodiesel for planes, with successful initial results [5], but all these processes of transformation in an industry as powerful will require years to consolidate and the clock is ticking against us.

In destinations like the Canary Islands tourist industry must make an effort to change into a more specialized destination of greater purchasing power tourists with longer stays, leaving aside the exclusive Sun and beach model very dependent on the prices of the packages that soon will be diverting to other destinations closer to the emitting countries with similar offers, the differentiation and exclusivity is our hope of salvation.

\section{Conclusion}

In view of the world energy panorama is easy to imagine that the air transport costs will increase gradually in the coming years, driven by the rise in prices of primary energy, if we look at the statistics of average expenditure per tourist and day for Canary Islands provided by the ISTAC [9] we observed that they have been gradually increasing in origin, this can lead us to a misinterpretation of the results thinking on a stable and growing future, however the trend of expenditure on destination is decreasing, as well as the cost per day of overnight hotel stays, this means that the cost of the tourist package has increased in relation to the transport and decreases in others. This is no more than an attempt to keep the average final price of the package on the basis that the destination assumes the difference, the problem is that this trend is continuous and progressively increasing which implies that sooner than later the increase of costs it must have to be assumed by the tourists. If we look at the Sun and beach destinations that move the greater number of tourists with very cheap packages "all-inclusive" becomes easily concluded that as transport costs increase and therefore media packages prices rise, we will see a gradual decline of the number of tourists in destination.

Insofar as soon as an alternative energy source is not listed, air transportdependent destinations have to make a major effort to adapt its airport facilities for aircraft of more capacity in order to reduce the cost/passenger and assumed a percentage of the loss of tourists with lower purchasing power in the coming years, on the other hand there is a second problem, in recent years the maintenance of lines and the majority of passenger air traffic has been supporting on new LC companies which usually operate on shorter radio and reduce maintenance costs by using the same aircraft model, do time, would these 
companies adapt its fleet of aircraft? or eventually ends up abandoning the destinations? The future is uncertain, but the reality is that the economy of the Canary Islands as an example of sun and beach tourism, inevitably depend on the evolution of air transport in the coming years.

\section{References}

[1] IDAE. Institute for the diversification and saving of energy. Analysis of energy consumption in the residential sector in Spain. (2012). www.idae.es.

[2] IDECanarias. Territorial Information System. Grafcan, visor sitcan. www.visor.grafcan.es.

[3] CODEXCA, consultant. Comparative analysis of air transport of products related to tourism in the Canary Islands. Government of the Canary Islands, Ministry of tourism. Canary Islands 2008.

[4] Carmen Salvador Durántez. Definition of indicators and sustainability models to evaluate the environmental impact of air transport. OBSA, Observatory of sustainability of aviation. Canary Islands 2010.

[5] UNWTO/UN Environment Programme (UNEP) Green Economy Report. 2011. www.unwto.org

[6] Grigolon, A.B., Kemperman, A.D.A.M. \& Timmermans, H.J.P. 2012, “The influence of low-fare airlines on vacation choices of students: Results of a stated portfolio choice experiment”, Tourism Management, vol. 33, no. 5, pp. 1174-1184.

[7] Castillo-Manzano, J.I., López-Valpuesta, L. \& Pedregal, D.J. 2012, “What role will hubs play in the LCC point-to-point connections era? The Spanish experience”, Journal of Transport Geography, vol. 24, pp. 262-270.

[8] Xavier Fageda, Juan Luis Jiménez, Carlos Díaz, Fare differences between domestic and international air markets on routes from Gran Canaria, Journal of Air Transport Management, Volume 25, December 2012, Pages 8-10, ISSN 0969-6997, 2012.

[9] ISTAC. Canary institute of statistics. Canary Islands Government. www.gobiernodecanarias.org/istac . 